\title{
The new patterns of nephrolithiasis: What has been changing in the last millennium?
}

\author{
Elisa Cicerello, Matteo Ciaccia, Gian D. Cova, Mario S. Mangano \\ Unità Complessa di Urologia, Dipartimento di Chirurgia Specialistica, Ospedale Ca' Foncello, Treviso, Italy.
}

\begin{abstract}
Summary Nephrolithiasis has been increasing over the last millennium. Although early epidemiologic studies have shown that kidney stones were two to three times more frequent in males than in females, recent reports have suggested that this rate is decreasing. In parallel a dramatic increase of nephrolithiasis has also been observed among children and adolescents. Furthermore, epidemiologic studies have shown a strong association between metabolic syndrome (Mets) traits and kidney stone disease. Patients with hypertension have a higher risk of stone formation and stone formers are predisposed to develop hypertension compared to the general population. An incidence of nephrolithiasis greater than $75 \%$ has been shown in overweight and obese patients compared to those of normal weight. It has also been reported that a previous diagnosis of diabetes mellitus increases the risk of future nephrolithiasis. Additionally, an association between metabolic syndrome and uric acid stone formation has been clearly recognized. Furthermore, 24-h urinary metabolic abnormalities have been decreasing among patients with nephrolithiasis over the last decades. Finally, nephrolithiasis could cause chronic kidney disease (CKD) and end stage renal disease (ESRD), especially in women and overweight patients. According to these observations, a better understanding of these new features among stone former patients may be required. Hence, the recognition and the correction of metabolic disorders could help not only to reduce the primary disease, but also stone recurrence.
\end{abstract}

KEY WORDS: Nephrolithiasis; Metabolic syndrome (Mets); Gender; Children; Adolescents.

Submitted 13 April 2021; Accepted 17 May 2021

\section{INTRODUCTION}

Several studies in the last decades have showed an overall increased incidence of kidney stones $(1,2)$. However, nephrolithiasis is increasing in women at a greater rate than in men and the common ratio 3:1 male to female is reducing $(3,4)$. An increased incidence of nephrolithiasis among children during the last 25 years has also been observed (5).

Moreover, other studies have shown Mets is increasing in parallel to the incidence and prevalence of nephrolithiasis (6). Various definitions have been included for defining Mets criteria. The United States National Cholesterol Education Program (NCEP) Adult Treatment Panel III (ATP III) is the most simple since it can be used by basic meta- bolic laboratories commonly present in clinics. Among five established criteria, three or more are needed to diagnose Mets. These are: waist circumference $>102$ and 80 $\mathrm{cm}$ in men and women respectively, serum triglycerides $>150 \mathrm{mg} / \mathrm{dL}$, high density lipoprotein $<40 \mathrm{mg} / \mathrm{dL}$ and $<50 \mathrm{mg} / \mathrm{dL}$ in men and woman respectively, blood pressure $(\mathrm{BP})>130 / 85 \mathrm{mmHg}$ and fasting blood sugar $<100$ $\mathrm{mg} / \mathrm{dL}$ (7) (Table 1). A study based on self-reported histories has shown an increasing association of nephrolithiasis and Mets traits (3.7\% with no traits, $7.5 \%$ for three traits and $9.8 \%$ for five traits) (8). Furthermore, the patients with more than 4 Mets traits also showed a significant increase in the chances of recurrent or multiple stones with respect to patients with 0 traits (9). Mets may also cause cardiovascular disease, a condition frequent in patients with nephrolithiasis (10).

These new insights confirm a new pattern of patients with nephrolithiasis that should be regarded as a systemic disease representing the result of the interaction of multiple risk factors.

This article will review the possible explanations for these new features of stone disease, with the aim to better assess them and their association with nephrolithiasis and to suggest measures for prevention not only for primary systemic disease, but also for stone recurrence.

\section{Mets and nephrolithiasis}

Obesity, the most frequent tract of Mets, is also a condition of risk for nephrolithiasis. A positive correlation between obesity and the first-time stone, recurrent stone formation and shorter interval of recurrence have been demonstrated. Taylor et al. have reported that waist circumference, body mass (BMI), weight gain, weight gain during adulthood are linked to an increase of incidental stones (11). Other studies have shown that BMI is higher in stone formers $(12,13)$. In a large cohort of women without history of stones the risk for incidental stones increases with BMI 1.3 fold for $25-29 \mathrm{~kg} / \mathrm{m}^{2}$ higher, 1.62 for $30-34.9 \mathrm{~kg} / \mathrm{m}^{2}$ and 1.81 fold for $\geq 35 \mathrm{~kg} / \mathrm{m}^{2}$ ) with respect to BMI $<25 \mathrm{~kg} / \mathrm{m}^{2}$ (14). Next, body fat can influence the risk for stone formation. Kim et al. have shown a link between uric acid and calcium oxalate stones and visceral adipose tissue measured on computed tomography (CT) (15). A link has also been reported between non-alcoholic fat liver disease and the risk of stone formation and visceral to subcutaneous fat tissue ratio (16).

No conflict of interest declared. 
Table 1.

NCEP ATP III: United States National Cholesterol Education Program.

\begin{tabular}{|l|l|}
\hline \multicolumn{2}{|l|}{ Adult treatment panel III, Rx, Pharmacologic intervention for that component } \\
\hline & Criteria \\
\hline Waist circumference $(\mathrm{cm})$ & $>102$ (males), $>88$ (females) \\
Fasting glucose (mg/dL) & $\geqq 100$ or Rx \\
Triglycerides (mg/dL) & $\geqq 150$ or Rx \\
High-density lipoprotein (mg/dL) & $<40$ (males), $<50$ (females) or Rx \\
Blood pressure (mmHg) & $>130$ (systolic), $>85$ (diastolic) or Rx \\
\hline
\end{tabular}

Additionally, obesity has been associated with impaired carbohydrate tolerance and inappropriate calcium response to glucose ingestion. Obese patients show an increased excretion of calcium, sodium, uric acid and a lower urinary $\mathrm{pH}$ in relation to the non-obese (17). Defects in renal ammoniagenesis and excessive net acid excretion (NAE), which are common in patients with Mets, could cause a decreased urinary pH (18). Next, renal acidification defects lead to hypocitraturia, another important risk for stone formation (13). Furthermore, an increased excretion of oxalate correlated with BMI has been reported among diabetic and overweight patients promoting calcium oxalate stone formation. Hence, both the percentage of uric acid and calcium oxalate stones was found higher in obese than non-obese patients (34.9 vs 23.1 and 7.7 vs 2.8 respectively) (19).

Diabetes mellitus has been clearly linked to nephrolithiasis. A previous diagnosis of diabetes increases the risk for stone formation and a previous diagnosis of stone disease leads to the onset of diabetes mellitus. In a crosssectional study of 3 large cohorts on multivariate analysis, the relative risk of prevalent stone disease in patients with type 2 diabetes was 1.38 in older women, 1.67 in younger women and 1.31 in men. Additionally, the risk of incident type 2 diabetes in patients with history of stone disease was $1.33,1.48$ and 1.49 respectively (20). Patients with type 2 diabetes have a decreased ammonium production resulting in lower urinary $\mathrm{pH}$ and increased risk of uric acid stone formation and an increased excretion of oxalate which promotes calcium oxalate stone formation (21). However, uric acid stones are more frequent in patients with diabetes and glucose intolerance (22). An association between the gravity of diabetes evaluated with fasting plasma insulin and glucose and hemoglobin Alc and the risk for stone formation has also been observed (23).

It is well known that elevated serum triglycerides and low high-density lipoprotein (HDL) levels increase the cardiovascular risk. Next, dyslipidemia is associated with lower urinary $\mathrm{pH}$ and could be considered as an independent risk factor for kidney stones (24). An association between dyslipidemia and kidney stone disease has been reported by Masterson and colleagues. This retrospective study shows an association between dyslipidemia and kidney stones with a hazard ratio of 2.2. Then, examining individually dyslipidemia factors, it was shown that low-density lipoprotein (LDL) and triglycerides are not associated with stone formation, while low
HDL values ( $<45 \mathrm{mg} / \mathrm{dL}$ for men; $<60 \mathrm{mg} / \mathrm{dL}$ for women) had a hazard ratio of 1.4 (25). Furthermore, nephrolithiasic patients show higher levels of total serum cholesterol and triglycerides (12). The association of total cholesterol with stone formation was higher in uric acid and calcium oxalate monohydrate/dihydrate. Besides, LDL levels were higher in calcium oxalate monohydrate/dihydrate stone formers than in calcium oxalate monohydrate group.

Several studies have shown an association between hypertension and nephrolithiasis: patients with hypertension are more at risk for nephrolithiasis (26) and patients with a history of nephrolithiasis have an increased risk for development of hypertension (27). Furthermore, hypertensive patients had a significantly increased calcium, oxalate and uric acid excretion with respect to normotensive controls $(26,28)$. Another study has shown stone formers with hypertension have reduced urinary excretion of citrate and urine $\mathrm{pH}$ and increased titrable acid excretion when compared with normotensive stone formers (29). The link between hypertension and stone disease could be high sodium dietary intake, common in hypertensive patients, promoting increased urinary excretion of calcium.

The association between cardiovascular disease and nephrolithiasis has also been recognized. A longitudinal study of patients affected by cardiovascular disease with follow-up more than 20-years has showed a correlation between cardiovascular features and stone disease (30). Next, a link between carotid atherosclerosis and kidney stone disease has also been observed. Another study by the Rochester Epidemiology Project spanning 10 years has found that calcium oxalate stone formers show a high risk of mortality from cardiovascular disease and higher total cholesterol, lower HDL, higher systolic blood pressure and elevated highly sensitive $\mathrm{C}$ reactive protein (hsCRP) (31). Calciuria and oxaluria have also been positively correlated with 10- year cardiovascular disease risk including mortality (32). Furthermore, a positive association between risk factors for coronary artery disease (smoking) was reported (33).

Finally, abdominal aortic calcification found on CT have been associated with uric acid stone formation, low urine $\mathrm{pH}$ and hypocitraturia (34).

\section{Gender and nephrolithiasis}

A new tract of this new epidemiology is the shifting in gender of nephrolithiasis. Although nephrolithiasis is still more frequent in men than in women, the ratio male to female is reducing and the most recent NHANES data showed an overall prevalence of $10.6 \%$ in men and $7.1 \%$ in women (35). The changing role of women in the workplace has been considered. Modification of lifestyle and dietary habits in relation to working activity could contribute to the shifting in gender difference of stone formation. Dietary factors promoting stone formation such as high animal protein, high salt and low calcium diets are more usual in men than in women, although the expansion of the high protein diet or higher fructose intake and low fluid intake to females could be a further cause of changing in gender of nephrolithiasis $(36,37)$. Obesity has also been associated with increased stone 
risk among women. Taylor et al. show that overweight among females increases the risk for stone disease with respect to men with the same characteristics. In this study, body mass, weight gain during adulthood as well as waist circumferences increased the risk of stone formation among females (11). It has also been reported that uric acid stones are present in more than $50 \%$ of obese females (38). Additionally, hyperinsulinemia, that is usually found in obese patients, may be associated to urinary acidosis with the consequent risk for uric acid stone formation (39). This could be the link between gender, obesity, insulin level and kidney stones. Another risk factor for stone formation among reproductive aged women is pregnancy. Reinstaller et al. have observed women with a history of pregnancy have more than twice the chance of stone formation than those who were never pregnant. Lithogenic factors such as hypercalciuria, hyperuricosuria and increased urinary $\mathrm{pH}$ have been observed during pregnancy. These data suggest that an increased lifetime lithogenicity could occur among females since many of them are pregnant in working age (40). Finally, it has been reported struvite and hydroxyapatite stones are more common in women aged less than 55 years (41). As urinary infections are increasing among females, they could be a factor for stone formation as well a further cause for the shifting in the gender of nephrolithiasis.

\section{Children and nephrolithiasis}

Another feature of the new pattern of nephrolithiasis is a dramatic increase of nephrolithiasis among children and adolescents over the past 25 years (42). A 25-year population based study performed in Olmsted County (Minnesota) has reported that $41 \%$ of children under the age of 18 showed incidence of stones on CT with an increase of 4\% of stones per year. Next, among 12-17 year olds the incidence rate was 6\% (43).

Database from the Healthcare Cost and utilization Project Kids' inpatient admission for pediatric nephrolithiasis in 2003 shows a higher frequency among girls. This difference in gender slightly changes in favour of boys within the first decade only (44). Another study in South Carolina has reported an increase to emergency department admissions for nephrolithiasis of children aged 0 to 18 years between 1996 to 2007 (5). The annual incidence of kidney stones was higher among school aged children and adolescents. In fact, the annual incidence rate among 14 to 18 years olds dramatically increased by about $50 \%$ from 1996 to 2007 ( 25 per 100.000 vs 54 per 100.000 respectively), while the incidence of stones for children younger than 9 years remained stable (less than 5 per 100.000). Moreover, among children and adolescents, girls had a higher incidence of kidneys stones than boys, as also reported by other studies (45). The reason for these features is not clear, probably because of the few cohort studies performed which have not allowed the analysis of the link between gender and risk factors.

Nephrolithiasis in children is idiopathic in origin in most cases, although rare genetic anomalies or a secondary cause of lithiasis such as neurological or congenital urinary anomalies of the urinary tract have also been identified. Besides, the risk of infected stones has decreased probably in relation to improved diagnosis and management of anatomical and neurological conditions promoting urinary infections. Conversely, environmental factors have been suggested in the pathogenesis of idiopathic nephrolithiasis. In fact, it has been reported that obesity and nephrolitihiasis among children are increasing in parallel (46). Dietary habits such as high intake of fructose (47) or salt (48) and low intake of fluid (49), which are the same risk factors for stone formation in adults, could be involved.

\section{Chronic kidney disease (CKD) and nephrolithiasis}

Nephrolithiasis has also been associated with CKD. Several studies have showed that, although kidney stones can cause CKD with acute or chronic damage of the urinary tract, the risk for end stage kidney disease (ESKD) or mortality from CDK are not increased (50). Data from the Alberta Kidney Disease network confirm similar results (51). Further cross-section analysis of NAHNES 2007 to 2010 has also reported a greater prevalence of CKD and ESRD in nephrolithiasis patients with odds ratios of 1.50 and 2.37 respectively (52). Specific conditions associated with the risk of CKD in stone formers have been analysed by Gambaro et al. (53). The results of this study have showed that nephrolithiasic patients have twice the risk of CKD or ESRD and the risk is higher in women and overweight stone formers.

\section{Comment}

There are changing patterns of nephrolithiasis. Shifting in gender prevalence and the increase of kidney stone disease among children and adolescents have been well observed. Moreover, a strong association between Mets traits and nephrolithiasis has been reported. Hence, it has been hypothesized that different metabolic alterations may modify urinary "milieu" through a common mechanism resulting in overly acidic urine with consequent salt precipitation and stone formation.

We have previously reported about metabolic disorders among 109 nephrolithiasic patients evaluated between 2017 and 2018 (54).

In this study metabolic urinary anomalies (hypercalciuria, hyperoxaluria, hyperuricosuria and hypocitraturia) in $24 \mathrm{~h}$ urine samples were observed only in 11 patients, while in a cohort of stone formers evaluated between 2007-2008 these figures were present in 28 of them. Conversely, metabolic disorders (hypertension, diabetes, dislypidemia, overweight) were present in $72 \%$ and more than 2 in $38 \%$ of the cases.

The decrease of urinary metabolic abnormalities observed in the group in the last decade could suggest that a complete metabolic evaluation is not necessary in all patients with associated comorbidities, while it may be performed in cases of relapses of stone events $(55,56)$.

The increase of metabolic disorders in the last decade confirm among nephrolithiasic the association between Mets and nephrolithiasis and supports the hypothesis that nowadays stone disease could be considered as a systemic disorder (Table 2)

Changes in lifestyle and dietary habits could have coincided with an increase of metabolic syndrome and in parallel of stone formation (57). Patients with Mets obvious- 
Table 2.

Summary of new patterns of nephrolithiasis.

The latest epidemiological studies have showed a change in gender distribution and an increasing prevalence among children and adolescents of nephrolithiasis.

The incidence and prevalence of kidney stones have been increasing in parallel with Mets, whereas rates of metabolic abnormalities diagnosed in 24-h urine is decreasing.

Nowadays, stone disease could be recognized not as a modification of urine composition or an ordinary flank pain, but as a systemic condition including Mets, cardiovascular diseases and CKD.

ly consume more food which could influence the urinary excretion of risk factors for stone formation. Preventative measures and careful patient education should be included to promote a healthy lifestyle. An increase of physical activity has been reported to prevent metabolic syndrome. Further, an increase of fluid intake to achieve a daily urinary volume of 2 litres and a diet rich in fruit and vegetable have reduced metabolic syndrome, stone formation and urinary infections $(58,59)$. Specific medical treatment (antidiabetics, antihypertensive, antilipemic and anticoagulant drugs) could be required to correct each component of metabolic syndrome (60).

\section{Conclusions}

The patterns of nephrolithiasis are changing.

Nephrolithiasis is still common among men, but the gender gap is narrowing as is the increase in occurrence among children and adolescents. With the parallel increase in incidence of both nephrolithiasis and systemic disorders, lifestyle changes with dietary and specific medicaments could be the most effective way to prevent primary disease and recurrent stone disease. Nephrolithiasis from ordinary flank pain could be recognized as a systemic condition and the correction of systemic disorders could not only reduce morbidity and mortality for diabetes, cardiovascular disease and development of CKD, but also minimize the risk of stone formation.

\section{REFERENCES}

1. Lieske JC, Pena de la Vega, Slezak JM, et al. Renal epidemiology in Rochester, Minnesota. Kidney Int. 2006; 69:760-764.

2. Pearle MS, Calhoun EA, Curhan GC. Urologic diseases in America project: urolithiasis. J Urol. 2005; 173:848-857.

3. Strope SA, Wolf JS jr and Hollenback BK. Changes in gender distribution urinary stone disease. Urology. 2010; 75:543-546.

4. Scales C Jr, Curtis LH, Norris RD, et al. Changing in gender prevalence of stone disease. J Urol. 2007; 177:979-982.

5. Sas DJ, Hulsey TC, Shataf IF, et al. Increasing incidence of kidney stones in children evaluated in the emergency department. J Pediatr. 2010; 157:132-137.

6. Wong Y, Cook P, Roderick P et al. Metabolic syndrome and kidney stone disease: a systematic review of literature. J Endourol. 2016; 30:246-253

7. Gorbachinsky I, Apikar H, Assimos DG. Metabolic syndrome and urologic disease. Rev Urol. 2010; 12e-157-e158.

8. West B, Luke A, Durazo-Arvizu RA et al. Metabolic syndrome and self-reported history of kidney stones: the national Health and Nutritional Examination Survey (NAHNES III) 1988-1994. Am J Kidney Dis. 2008; 51:741-747.
9. Khjimoto Y, Sasaki Y, Iguchi M, et al. Association of metabolic syndrome traits and severity of kidney stones: results of nationwide survey on urolithiasis in Japan. Am J Kidney Dis. 2013; 61:923-929.

10. Boyd C, Wood K, Whitaker D et al. The influence of metabolic syndrome and its components on the development of nephrolithiasis. As J Urol. 2088; 5:215-222.

11. Taylor EN, Stampfer MJ, Curhan GC. Obesity, weight gain, and the risk of kidney stones. JAMA. 2005; 293:455-462.

12. Inci $M$, Demirtas A, Sarli B, et al. Association between body mass index, lipid profiles, and types of urinary stones. Ren Fail. 2012; 34:1140-1143

13. Cupisti A, Meola M, D'Alessandro C, et al. Insulin resistance and low urinary citrate excretion in calcium stone formers. Biomed Pharmacother. 2007; 61:86-90.

14. Sorensen MD, Chi T, Shara NM, et al. Activity, energy intake, obesity, and the risk of incident kidney stones in post-menopausal women: a report from the Women's Health Initiative. I Am Soc Nephrol. 2014; 25:362-369.

15. Kim JH, Doo SW, Yang WJ, et al. The relationship between urinary stone components and visceral adipose tissue using computed tomography-based fat delineation. Urology. 2014; 84:27-31.

16. Nam IC. Association of non-alcoholic fatty liver disease with renal stone disease detected on computed tomography. Eur J Radiol Open. 2016; 3:195-199.

17. Trinchieri A, Croppi E, Montanari E. Obesity and urolithiasis: evidence of regional influences. Urolithiasis. 2017; 45:271-278.

18. Maalouf NM, Cameron MA, Moe OW, et al. Low urinary $p H$ : a novel feature of the metabolic syndrome. Clin J Am Soc Nephrol. 2007; 2:883-888.

19. Chou YH, Su CM, Liu CC. Difference in urinary stone components between obese and non-obese patients. Urol Res 2011; 39:283-287.

20. Taylor EN, Stampfer MJ, Curhan CG. Diabetes mellitus and the risk of nephrolithiasis. Kidney Int. 2005; 68:1230-1235.

21. Eisner BH, Porten SP, Bechis SK, et al. Diabetic kidney stone formers excrete more oxalate and have lower urine $\mathrm{pH}$ than nondiabetic stone formers. J Urol. 2010; 183:2244-2248.

22. Sakhaee K, Adams- Huet B, Moe OW, et al. Pathophysiologic basis for normouricosuric uric acid nephrolithiasis. Kidney Int. 2002; 62:971-979.

23. Weinberg AE, Patel CJ, Chertow GM et al. Diabetic severity and risk of kidney stone disease. Eur Urol. 2014; 65:242-247.

24. Torricelli FC, De S, Gebreselassie SK, et al. Dyslipidemia and kidney stone risk. J Urol. 2014; 191:667-672.

25. Masterson JH, Woo JR, Chang DC, et al. Dyslipidemia is associated with an increased risk of nephrolithiasis. Urolithiasis 2015; 43:49-53.

26. Borghi L, Meschi T, Guerra A, et al. Essential hypertension in stone disease. Kidney Int. 1999; 55:2397-2406. 
27. Kittanamongkolchai W, Mara KC, Mehta RA, et al. Risk of hypertension among first time symptomatic kidney stone formers. Clin J Am Soc Nephrol. 2017; 12:476- 482.

28. Mente A, Honey RJ, Mc Laughlin JM, et al. High urinary calcium excretion and genetic susceptibility to hypertension and kidney stone disease. J Am Soc Nephrol. 2006; 17:2567-2575.

29. Losito A, Nunzi EG, Covarelli C, et al. Increased acid excretion in kidney stone formers with essential hypertension. Nephrol Dial Transplant. 2009; 24:137-141.

30. Reiner AP, Kahn A, Eisner BH, et al. Kidney stones and subclinical atherosclerosis in young adults: the CARDIA study. J Urol. 2011; 185:920-925.

31. Rule AD, Roger VL, Melton LJ, et al. Kidney stones associate with increased risk for myocardial infarction. AM J Soc Nephrol. 2010; 21:1641-1644.

32. Aydin H, Yencilek F, Erihan IB, et al. Increased 10-year cardiovascular disease and mortality risk scores in asymptomatic patients with calcium oxalate urolithiasis. Urol Res. 2011; 38:451-458.

33. Hamano S, Nakatsu H, Suzuki N, et al. Kidney stone disease and risk factors for coronary stone disease. Int J Urol. 2005; 12:859-863.

34. Patel ND, Ward RD, Calle J, et al. Vascular disease and kidney stones: abdominal aortic calcifications are associated with low urine pH and hypocitraturia. J Endourol. 2017; 31:956-961.

35. Scales C Jr, Smith AC, Hanley JM, et al Prevalence of kidney stones in the United States. Eur Urol. 2012; 62:160-165.

36. Tundo G, Khaleel S, Vernon MP Jr. Gender equivalence in the prevalence of nephrolithiasis among younger than 50 years in the United States. J Urol. 2018; 20:1273-1277.

37. Cicerello E, Mangano MS, Cova GD, et al. Changing in gender prevalence of nephrolithiasis. Urologia. 2021; 88:90-93.

38. Moses RA, Pais VM, Ursiny M, et al. Changes in stone composition over two decades: evaluation of over 10.000 stone analysis. Urolithiasis. 2015; 43:135-139.

39. Abate N, Chandalia M, Cabo-Chan AV Jr, et al. The metabolic syndrome and and uric acid nephrolithiasis: novel feature renal of manifestation of insulin resistance. Kidney Int. 2004; 65:386-392.

40. Reinstatler L, Khaleel, Pais VM Jr. Association of pregnancy with stone formation among women in the United States: a NAHNES analysis 2007 to 2012. J Urol. 2017:198:389-393.

41. Lieske JC, Rule AD, Kramberk AE, et al. Stone composition as a function of age and sex. Clin J Am Soc Nephrol. 2014; 9:2141-2146.

42. Routh JC, Graham DA, Nelson CP. Epidemiological trends in pediatrics urolithiasis at United States freestanding pediatrics hospitals. J Urol. 2010; 184:1100-1104.

43. Dwyer ME, Krambeck AE, et al. Temporal trends in incidence of kidney stones among children: a 25-year population based study. J Urol. 2012; 188:247-252.

44. Novak TE, Lakshmanan Y, Trock BJ, et al. Sex prevalence of pediatric kidney stone disease in United States: an epidemiological investigation. Urology. 2009; 74:104-107.

45. Bush NC, Xu L, Brown BJ, et al. Hospitalization for pediatric stone disease in United States, 2002-2007.J Urol. 2010; 183:11511156.

46. Ogden CL, Carroll MD, Kit BK, et al. Prevalence of obesity and trends in body mass index among US children and adolescents, 1999-2010. JAMA. 2012; 307:483-490.

47. Vos MB, Kimmons JE, Gillespie C, et al. Dietary fructose con- sumption among US children and adults: the Third National Health and Nutrition Examination Survey. Medscape J Med. 2008; 10:160-177.

48. US Institute of Medicine. Strategies to reduce sodium intake in the United States. National Academic of Sciences. 2010. Available from: hhp:// www.iom.edu/Reports /2010/Strategies-to-Reduce Sodium Intake-in-the-United-States/Report-Brief-Strategies-toReduce-Sodium-Intake-in-the-United-States.aspx.

49. Kant AK, Graubard BI. Contributors of water intake in US children and adolescents: associations with dietary and meal characteristics- National Healthand Nutrition Examination Survey 20052006. Am J Clin Nutr. 2010; 92:887-896.

50. El-Zoghby ZM, Lieske JC, Foley RN, et al. Urolithiasis and the risk of ERSD. Clin J Am Soc Nephrol. 2012; 7:1409-1415.

51. Alexander RT, Hemmelgarn BR, Wiebe Net al. Kidney stones and kidney function loss: a cohort study. BMJ. 2012; 345:e5287.

52. Shoag J, Halpern J, Goldfarb DS, et al. Risk of chronic and stage kidney disease in patients with nephrolithiasis. J Urol. 2014; 192:1440-1445

53. Gambaro G, Croppi E, Bushinnsky D, et al. The risk of chronic kidney disease associated with urolithiasis and its urological treatment: a review. J Urol. 2017; 198:268-273.

54. Cicerello E, Mangano MS, Cova GD, Ciaccia M. Changing pattern in nephrolithiasic patients: our experience. Eur Urol Suppl. 2019; 18:e2073-e-2074,

55. Abu-Ghanem Y, Shvero A, Kleinman N, et al. 24-h urine metabolic profile: is necessary in all kidney stone formers? Int Urol Nephrol. 2018; 50:1243-247.

56. Cicerello E, Mangano MS, Cova GD, et al. Metabolic evaluation in patients with infected nephrolithiasis: is it necessary? Arch Ital Urol. 2014:86:257-269.

57. Perletti G, Magri V, Ferraro PM, Montanari E, Trinchieri A. Influence of dietary energy intake on nephrolithiasis - A metaanalysis of observational studies. Arch Ital Urol Androl. 2020;92:30-33

58. Ford ES, Kol HW III, Mokdad AH, et al. Sedentary behavior, physical activity, and the metabolic syndrome amomg U.S. adults. Ob Res. 2005; 3:608-614.

59. Prezioso D, Strazzullo P, Lotti T, et al. Dietary treatment of urinary risk factors for renal stone formation. A review of CLU Working Group. Arch Ital Urol Androl. 2015; 87:105-120.

60. Wagh A, Stone NJ. Treatment of metabolic syndrome. Exp Rev Cardiov Ther. 2008; 2:213-228.

\section{Correspondence}

Elisa Cicerello, MD

elisa.cicerello@tin.it

Matteo Ciaccia, MD

Gian D. Cova, MD

Mario S. Mangano, MD

Unità Complessa di Urologia, Dipartimento di Chirurgia Specialistica,

Ospedale Ca' Foncello, Treviso, Italy 